Rada Cossutta

Visoka šola modernih jezikov za tolmače in prevajalce, Univerza v Trstu

\title{
Romanske izposojenke v poljedelski terminologiji Slovenske Istre
}

Gradivo, ki ga avtorica $\mathrm{v}$ tem prispevku etimološko utemeljuje $\mathrm{z}$ vidika romanizmov $\mathrm{v}$ poljedelskem izrazju govorov Slovenske Istre, je kratek povzetek njene doktorske disertacije z naslovom Poljedelska in vinogradniška terminologija $v$ govorih Slovenske Istre. Namen razprave je ugotoviti tokove istrske romanizacije in začrtati jezikovno podobo tega ozemlja.

The material in this article presents Romance borrowings, treated etymologically, in the domain of the agricultural terminology of the dialects of Slovene Istria; as such, it is a summary of the author's doctoral dissertation entitled Agricultural and Viticultural Terminology in the Dialects of Slovene Istria. The purpose of the study is to reveal of the paths of Istrian Romanization and to delineate the linguistic geography of the region.

Jezikovna podoba Slovenske Istre je pestra in zapletena, kakor je zapletena tudi njena zgodovinska preteklost. Politična slika te pokrajine se je namreč v zadnjih stoletjih večkrat spreminjala, kar se še danes odraža $v$ jeziku. $Z$ vidika narečnih raziskav je bilo to ozemlje, na katerem se križata vsaj dva slovenska govora (rižanski in šavrinski), do nedavnega nekoliko zanemarjeno. Zato sem v letih 1988-90 pod mentorstvom prof. Tineta Logarja za svojo doktorsko disertacijo zbrala približno deset tisoč besed $\mathrm{s}$ področja poljedelskega in vinogradniškega izrazja na podlagi specifične vprašalnice, ki sem jo, $\mathrm{z}$ dodatkom nekaterih lastnih vprašanj (RC), priredila po vprašalnici Italijanskega lingvističnega atlasa (ALI), Historično-lingvistično-etnografskega atlasa Furlanije-Julijske krajine (ASLEF) in Slovenskega lingvističnega atlasa (SLA). Upoštevala sem izrazoslovje različnih kmetijskih panog in tako razdelila zbrano gradivo na 7 poglavij (I. Kmečko orodje, pridelki, delo na polju in v hlevu; II. Na vrtu in v sadovnjaku; III. Vinogradništvo; IV. Nekatere rastline in drevesa in opravila z njimi; V. Reja živali; VI. Čebelarstvo; VII. Oljarstvo).

Terensko delo sem izvedla postopoma v 10 raziskovalnih točkah: 1. Malija; 2. Padna; 3. Krkavče; 4. Gažon; 5. Smarje; 6. Koštabona; 7. Pomjan; 8. Boršt; 9. Marezige; 10. Trebeše. Na tem območju, ki je že od nekdaj stičišče romanske in slovanske kulture, se neprestani medsebojni vplivi kažejo zlasti v leksiki. Ker so romanizmi zastopani skorajda $\mathrm{v}$ izrazoslovju vsake kmetijske panoge, je njihova podrobna analiza sredstvo za boljše poznavanje jezikovnih tokov, ki so v različnih obdobjih vplivali na narečno diferenciacijo tega dela slovenskega ozemlja. Pri razčlembi romanskih izposojenk sem ugotovila več plasti:

1. latinsko plast, v katero spadajo nekatere kulturne besede in latinske izposojenke iz različnih obdobij;

2. beneško plast, ki je zelo vitalna in pomensko razvejana, kar gre pripisati dolgoletni beneški nadvladi na tem ozemlju; 
3. istrskoitalijansko in tržaškoitalijansko plast, za katero je značilen pojav prevzema slovenskih deminutivnih pripon oz. poslovenjenja glagolskih nedoločniških in deležniških pripon ter dodajanje slovenskih glagolskih predpon (isti pojav zasledimo tudi pri beneški plasti);

4. italijansko plast, v katero uvrščam izraze, ki so brez vidnejših fonetičnih in morfoloških sprememb prevzeti iz knjižne italijanščine;

5. furlansko plast, ki sega od srednjeveške (tergestinske in muglizanske izposojenke) do novoveške, pri kateri pride v poštev zlasti vpliv bizjaškega in furlanskega govora.

Naslednje primere romanizmov, ki nedvomno potrjujejo razslojenost istrskoslovenskega besedišča, sem izluščila iz zbranega gradiva za kmečko orodje.

3. Dvojni plug; aratro a due ali; Q. ALI 3547:

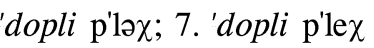

Izposojeno iz furl. adj. dòpli 'dvojen' (DESF II 637 d.; NP 266), ki ga lahko primerjamo tudi z istopomenskim mugl. dóplo (DDM 36), arh. trž. in istr.it. (Labin) agr. duplo (prim. it. doppio, trž. dopio), ki je bil v rabi tudi kot pravni termin; prim. conto in duplo (Rosamani 335), ben. subst. f. dupla 'dvojni seznam' (Boerio 249). Battisti in Alessio uvrščata adj. duplo med učene izraze ('voce dotta') (DEI II 1403). Zadnji vir navedenih terminov je lat. dŭplus (DEI II 1383; DELI 2, 362; REW 2802).

9. Ročice; stegole (stive) dell'aratro; Q. ALI 3551:

3. mə'nicȧ; 4. mə'nice; 6. ma'nice; 8. ma'nica; 10. ma'nice V zvezi s trž. maniza Doria (GDDT 356) ugotavlja, da bi nas končica -ica lahko zavedla $\mathrm{v}$ povezavo $\mathrm{s}$ slov. deminutivom. $\mathrm{V}$ resnici je to beseda pristno rom. izvora (iz lat. *manīcia $=$ manı̌cia $)$, ki je prešla $\mathrm{v}$ slov. istr. govore verjetno tudi s posredovanjem ben. narečij, kjer je splošno razširjena $\mathrm{v}$ pomenu 'kljuka', podobno kot $\mathrm{v}$ tržaščini. V rom. istrskih govorih je izpričana tudi varianta manisa, ki je v Kopru že dobila specifični pomen 'ročica pri plugu' (Rosamani 585), ki ga srečujemo tudi v slov. istr. govorih.

13. Obračalni plug, obračalnik; sarchiatore; Q. ALI 3554-1:

a) 3. fər'šor

Izposojeno prek istr.it. (Koper, Rovinj) versór 'plug, obračalnik' (Rosamani 1215 d.; Semi 300) iz beneč. versôr 'id.', katerega izhodišče je lat. barb. versōrium oz. lat. versor, -aris 'obrniti se' (Boerio 789). Sorodno je tudi furl. varsór 'plug' (TAF 20) oz. versôr 'id.' (NP 1269).

b) 6. šfalca'dọr

Oblika je prevzeta iz trž.it. falzador 'kosec', ki je izoliran termin, prikrojen po ustrezni it. obliki falciatore 'id.' (GDDT 223) z dodatkom protetičnega $\check{s}^{-}$-, ki ga srečujemo tudi v sorodnih istr.it. oblikah, prim. istr.it. (Koper, Piran) sfalsar 'kositi' (Rosamani 1012; Semi 290), (Koper) sfalseto 'srp' (Semi ibid.) itd. Pomensko prestavo slov. istr. oblike pa je mogoče razložiti le s križanjem s furl. solzadôr 'vrsta pluga $\mathrm{z}$ manjšim lemežem (it. vangheggia)' (NP 1067; Rosamani 1050) kot izvedenko iz lat. sulcus, -are (TAF 50; REW 8442). 
14. Lopata; vanga; Q. ALI 3555:

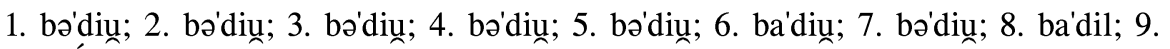
ba'dií; 10. bo'dij

Beseda, ki je prisotna na vsem sev.it. območju in je nato prešla tudi $\mathrm{v}$ knjižno italijanščino (badile 'lopata', DEI I 402), je izvedena iz vulg. lat. batīle oz. lat. batīllum 'lopata' (REW 992; DEI ibid.) in je splošno razširjena z istim pomenom: prim. beneč. bail (Boerio 56), emil. in breš. badil, trž.it. in milj.it. badil (GDDT 46), istr.it. (Koper, Veliki Lošinj) badil (Rosamani 54), furl. badîl (DESF I 136; NP 30), čeprav manj splošno (TAF 64 d.). Verjetno je prek tržaščine prešla na Kras (Pleteršnik I 38 navaja bodil, SDLA-Ts 398 pa druge variante) in v slov. istrske govore.

15. Lopatati; vangare; Q. ALI 3564:

*1. 'bädələt; 2. 'bədlət; 3. 'bảdlət; 5. 'bảdĺət; 6. bəd'ĺat

Oblika je vsekakor izvedenka (za eti. gl. vpr. 14). Sorodno je trž.it. in milj.it. badilar 'delati z lopato; kopati z lopato' (GDDT 46), furl. (redko) badilâ(r) 'id.' (DESF I 136; TAF 67), toda nedoločniška pripona slov. istr. oblik je tipično slovenska.

16. Železni del pri lopati; vangile; Q. ALI 3557 :

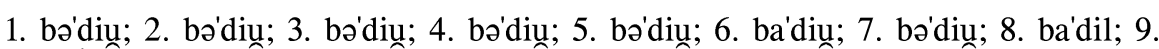
ba'diĺ; 10. bo'dij (za eti. gl. vpr. 14)

18. Brana; erpice, treggia; Q. ALI 359:

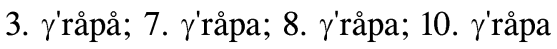

Rosamani (Rosamani 452) navaja obliko grapa 'brana' tudi za istr.it. (Koper, Buje) in bizj. (Fogliano, Monfalcone) poleg pogostejše furl. oblike gràpe $\mathrm{z}$ istim pomenom (NP 400 d.; TAF 68), vse iz germ. *krappa 'kavelj' (REW 4760 s pridržkom; Bezlaj I 171 pod geslom gräp). V resnici gre za termin, ki je splošno razširjen na ben. in trent. območju s pomenom 'brana': prim. beneč. (Boerio 315), vič., trev., valsug. in belun. grapa (Prati EV 78).

19. Branati, vlačiti; erpicare; Q. ALI 3560:

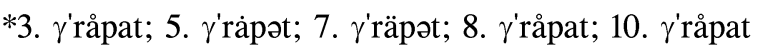

Vzporedno s terminom gràpe/- $a \mathrm{f}$. se na skoraj vsem furlanskem območju uporablja glagol grapâ (NP 400; TAF 72 d.), na beneškem pa grapar (Prati EV 78) 'branati', ki je prešel tudi v istr.it. (Koper) grapar 'id.' (Rosamani 452; Semi 259). Ta izvedenka (s tipično slov. nedoločniško pripono -at/-ət) je prisotna tudi v slov. istr. oz. slov. furl. govorih (prim. Cergnéu grapate; Vernasso grapat) (TAF 72 d.), medtem ko ni izpričana v slovenščini.

22. Rovnica; zappa; Q. ALI 3563:

a) 2. štər'påča 
$\mathrm{Z}$ adaptacijo pripone izposojeno iz istr.it. (Piran) sterpaza 'poseben tip kmečkega orodja nekje sredi med rovačo in krampom' (Rosamani 1092); prim. tudi varianti: istr.it. (Vodnjan) stropasa 'kmečko orodje: poseben tip rovače s širokim in kratkim železnim delom, s katero obdelujejo teren le površinsko' (Rosamani 1110) in istr.it. (Fažana, Rovinj) strupasa 'rovača (poseben tip lopate, ki služi za odstranjevanje kamenja na njivah)' (Rosamani 1112); vse izvedeno iz istr.it. (Motovun) sterpar '(iz)trebiti' (Rosamani 1092), to pa iz it. arh. sterpare 'id.', katerega zadnje izhodišče je lat. exstirpāre (DEI V 3632).

b) 6. ša'pẹta ('manjša rovnica')

Istr. dem. ša'pẹta je ben. izposojenka: prim. ben. *zapéta/sapéta 'majhna šapa' (Turato-Durante 175 in 258); trž.it. zapeta 'majhna motika' (GDDT 797); beneč. zapèto 'kopača' (Boerio 806); furl. (Fogliano) zapeta 'id.' (Rosamani 1244).

24. Kopača; sarchio, bidente; Q. ALI 3565:

10. sə’pọn

Prevzeto prek istr.it. (Rovinj, Vodnjan, Buje) sapon 'šapa' (Rosamani 1244) iz ben. oz. furl.: prim. kjož., belun. arh. sapon 'velika šapa; kramp' (Tomasi 166); beneč. zapòn 'id.' (Boerio 806); furl. sapòn 'id.' (NP 927); trž.it. zapon 'id.' (GDDT 798); ben. dalm. zapòn 'id.' (Miotto 221).

\section{Rovača, kramp; piccone; Q. ALI 3566:}

a) 1. 'pink

Istr. slov. pink (z epentetskim - $n$-) je verjetno sorodno s furl. (Raveo, Cavolano) pic 'nekoliko manjši kramp' (NP 748 pod geslom picòn; TAF 86); prim. tudi ben. pico 'kramp' (Durante 378) in istopomenska frc. pic, it. picco (DEI IV 2903), vse iz osnove * pikk- 'konica'.

b) 2. pi'kuọn; 3. pi'kọn; 4. pi'kọn; 5. pi'kọn; 6. pi'kọn; 7. pə'kọn; 8. pi'kọn; 9. pi'kuọn; 10. pi'kọn

Beseda, ki je sicer splošno v rabi v vseh ben. govorih [prim. ben. picón/pico 'kramp' (Durante 378); beneč. picon 'id.' (Boerio 506)], v večjem delu Furlanije, [prim. furl. picòn 'id.' (NP 748; TAF 86)] in v it. knj. jeziku [prim. it. knj. piccóne 'id.' (DEI IV 2903)], je v slov. istr. in kraš. govore prešla verjetno prek istopomenskega trž.it. picon (GDDT 463). Vsi navedeni izrazi so seveda avgmentativi iz osnove * pikk- 'konica'.

29. Železni obroček pri kosi; ghiera della falce; Q. ASLEF 3218 Complemento:

1. 'birja; 2. 'birja; 3. 'birjå; 4. 'birja; 5. 'birjå; 6. 'birja; 7. 'birja; 8. 'birja; 9. 'birjå; 10. 'birja

Bezlaj (Bezlaj I 22) pod geslom bîrja ‘železen obroč; okov pri nožu, kosi, vozu’ navaja še dubleto vírja, dem. bîrjica, dial. (Kras) biérja, kor. biarja, istr.čak. birica 'annulus ferrus'. Vse izposojeno iz rom.: stit. viria 'obroček' (DEI V 4064) prek poznolat. viria iz lat. f. pl. viriae (po Pliniju keltska substratna oblika); prim. tudi stit. viera, it. ghiera, trž.it. vera 'prstan' (GDDT 780), furl. vère, viérie, viara 'obroček' (NP 1266 d.). 
30. Kljuka (za desno roko); presacchio (impugnatura) della frullana per la mano destra; Q. ALI 3570:

9. ma'nicå od 'dẹsnả (za eti. gl. vpr. 9)

31. Ročica (za levo roko); presacchio della frullana per la mano sinistra; Q. ALI 3571:

9. mánicå od 'lẹvá (za eti. gl. vpr. 9)

35. Rezilo (kosa) pri slamoreznici; falcione, falce a panca; Q. ALI 3574:

5. 'lamå; 10. 'låma

Prek trž.it. lama 'rezilo' (GDDT 319; Rosamani 522) izposojeno iz it. lama ‘jeklo za rezilo; rezilo' (DEI III 2153); prim. tudi furl. (Belvedere) làma dal falsòt 'rezilo pri kosi' (TAF 105); vse iz lat. lämina 'plošča, ploščica' (DEI ibid.).

36. Slamoreznica; trinciapaglia; Q. ALI 3574-1:

1. 'makińa zə 'rẹzət s'lamọ; 3. 'makińå, kə 'sečiå s'lamu

Istr. slov. makińa je zaradi palatalizacije prikrojena oblika ustrezne it. knj. oblike màcchina 'stroj, naprava' (DEI III 2298), ki jo srečamo tudi v trž. màchina 'stroj (v splošnem pomenu)' (GDDT 343) in in istr.it. màchina 'id.', v Rovinju in Balah tudi v pomenu 'mlatilnica' (Rosamani 561; Cernecca 61); vse iz lat. māchina (DEI ibid.). Palatalizacija istr. slov. oblike je nastala verjetno pod vplivom furl. màchigne 'stroj; mlatilnica' (NP 544).

37. Vejnik; pennato; Q. ALI 3575:

a) 3. fəl'cetå

Iz istr.it. (Oprtalj) falzeta 'vinóraz, vinjek (z rezilom v obliki srpa)' oz. (Poreč) falseta 'id. (toda z zakrivljenim rezilom)' (Rosamani 354); prim. tudi trž.it. falzeto, (Škedenj) falzet, folzet 'vinóraz' (GDDT 223) in furl. falzèt/falzut 'kosa različnih oblik in za različne rabe' (NP 293), vsi deminutivi iz it. falce 'srp, kosa' (DEI II 1585), stit. falcia oz. ben. falza 'id.' (DEI II 1586), iz lat. falce(m) prek metaplazme (GDDT ibid.).

b) 5. ronko'nelå; 7. rənkə'nela

Iz istr.it. (Piran) ronconela 'rončelica, krivec' (Rosamani 895); prim. tudi furl., sicer malo razširjeno, ronkonéle 'sekač' (TAF 126), ki je povezano s furl. roncâ 'obrezovati', ben.it. roncare 'pleti (s srpico)' oz. lat. rŭncāre 'id.', iz katerega izhajajo tudi istrske oblike (GDDT 533 pod geslom roncola; DEI V 3280).

c) 9 . 'rånčolå

Istr. slov. izraz, ki je soroden s kraš. rančal 'sekač' (SDLA-Ts 416), je morda prikrojen po furl. roncèe 'vejnik, sekač' (NP 896; Zamboni, Romanismi 131). Zadnji vir je lat. *runcŭlia, to pa iz lat. rŭncāre 'pleti', prim. it. roncare (DEI V 3280; REW 7444).

38. Sekač; ronca, roncola; Q. ALI 3576: 
a) 1. ronko'nẹla; 2. ronkə่nẹla; 4. ronkə่nela; 5. 'ročnå ronko'nelå; 7. rənkə่nela (za eti. gl. vpr. 37b)

b) 3. fal'cetå; 6. fal'cẹta (za eti. gl. vpr. 37a)

39. Krivec; roncolo; Q. ALI 3577:

2. rə'zilo zə škar'šẹlu

Prevzeto iz trž.it. in istr.it. (Koper) scarsela 'žep' (GDDT 581 d.; Rosamani 963), ki je beseda širšega ben. areala: prim. istopomensko bizj. scarsela (Domini 412), ben. (tudi beneč.) scarsèla (Boerio 621; Durante 481; Prati EV 156) oz. stit. scarsèlla 'usnjena torba za denar', ki je negotovega porekla (DELI 5, 1146). Prati (Prati ibid.) domneva, da je treba izhajati iz it. adj. scarso 'skop', ker je ta torba služila za prihranke.

48. Nečke; paniera, vassoia, capisteo (a valva di conchiglia); Q. ALI 3587:

a) 1. plə'niẹr; 2. plə'nier; 4. plə'nier; 6. pla'nier; 7. pla'nier; 8. plə'nier; 9. pla'niẹr Istrske oblike se, podobno kot kraš. planier 'nečke' (SDLA-Ts II 426), zelo verjetno navezujejo na terg. planer 'jerbas' (Rosamani 804), ki je rezultat križanja lat. pānārium 'košara za kruh', iz katerega izhajajo tudi it. panière 'košara iz vrbovja', frc. panier 'košara, jerbas' (DEI IV 2747 d.; REW 6187) in trž.it. oz. istr.it. pianer 'košara za kruh' (GDDT 458; Rosamani 776), in lat. plēnus 'poln' (GDDT ibid.).

b) 5. pa'nier

Istr. slov. pa'nier je, podobno kot istr.it. (Kanfanar, V. Lošinj) paner (GDDT 458), prevzeto iz it. knj. panière 'košara iz vrbovja' (DEI IV 2747 d.); prim. tudi frc. panier, furl. panàrie 'krušna skrinja' (NP 691), vse iz lat. pānārium 'košara' (REW 6187).

49. Vejati, čistiti žito; mondare il grano; Q. ALI 3588:

*6. 'baratat; 9. 'bäratat

Čeprav ima istr. izvedenka tipično slov. nedoločniško pripono in notr. preskok akcenta (stara oblika baratát), se očitno navezuje na sorodne sev.it. izraze, ki so vsi prilagojeni po it. burattare 'presejati', ta izhaja iz it. buratto 'sito', vse pa iz *bura (DEI I 636; REW 1398): prim. istr.it. (Koper) buratar 'presejati' (Rosamani 131), beneč. buratàr 'id.' (Boerio 107), ben. buratàre 'id.' (Durante 59), trev. buratàr 'id.' (Bernardi 101), furl. buratâ 'id.' (NP 83), bizj. istopomensko buratar (Domini 66; TAF 163) .

50. Lopata za žito; pala da grano, batillo; Q. ALI 3589:

a) 1. 'šešla; 2. 'šiẹšla; 3. 'šẹšolå

Istr. šešola, ki se je nato razvilo v šešla/šiešla, je splošno v rabi v istr.it. (Rosamani 1010) in ben. govorih (vič., padov., kjož., beneč., ver., rover., trev.), kjer sèssola označuje lopatico za zajemanje vode iz barke oz. moke iz krušne skrinje (Bernardi 386; Boerio 649; Durante 508); prim. tudi trž.it. sèsola 'lesena ali kovinasta zajemalka za žito' (GDDT 615), ben.dalm. sèfola 'lopatica' (Miotto 188), vse iz it. sèssola pom. 'lesena lopata za zajemanje vode' oz. srlat. sessa, sesula 'id.', o katerem Pelleg- 
rini (Pellegrini 'Riv. St. Calabr.' N. S. 3 (1982), str. 345 d.) domneva, da izhaja iz arab. satl ali setl 'vaza z ročajem', ta pa iz lat. situla. Spet drugi trdijo, da je izvor besede negotov, mogoče onomatopejski (DEI V 3466 d.).

b) 4. 'šešula; 5. 'šešulå; 6. 'šešula; 7. 'ročna 'šẹ̌sula; 8. 'šešula; 9. 'šešulå;

Istr. šešula izhaja iz istr.it. (Labin, M. Lošinj) sèssula 'lopatica', nekoč v rabi tudi v Tržiču (Monfalcone) v pomenu 'lopatica za vino' (Rosamani 1010) oz. (Rovinj) sièssula (Rosamani 1028); prim. tudi furl. sèssule/siéssule 'lesena lopatica z zelo kratkim ročajem za odstranjevanje vode (iz barke) ali vina (na dnu bednja)' (NP 1040). Za eti. gl. vpr. 50a.

c) 10. 'čẹšula

Istr. čẹšula se verjetno navezuje na dalm. hrv. češula (J. Božanić, Čak. rič 11 (1983), str. 6), ki je ben. izvora (GDDT 615).

58. Dno voza; piano (letto) del carro; Q. ALI 3597:

a) 1. tavo'lac; 2. tavo'lac; 4. tavo'laco; 5. tavo'låco; 7. tavo'laco

Istr. tavolac se navezuje na istr.it. (Labin) oz. trž.it. tavolaz 'ležišče na deskah' (GDDT 726; Rosamani 1143), ki sta prikrojitev it. tavolàccio 'id.' (DEI V 3733), medtem ko je istr. varianta tavolaco splošno v rabi v it.istr. govorih (Labin, Poreč, V. Lošinj, Krk) v pomenu 'deščeni oboj voza' (Rosamani 1143) in v trž.it. dialektu kot 'deščeni oboj, pod' (GDDT 726), iz it. knj. tavola 'deska'.

b) 6. ška'leta

Beseda je trž. izposojenka: iz trž.it. scaleta 'lestvica', deminutivne oblike trž.it. scala 'lestev' (GDDT 573), ki je tipični italijanizem; glede istr. pomena 'dno voza' prim. tudi furl. (Racchiuso) sk'aléte 'lestvica' (TAF 280). Poimenovanja za 'dno voza' povezana $\mathrm{z}$ izrazom scala so razširjena tudi v drugih it. pokrajinah (TAF ibid.).

c) 9 . š'kålå

Beseda, ki je sicer v slov. istr. govorih doživela semantično prestavo, ki je v zvezi z nazivom scala za 'dno voza' značilna tudi za nekatera sev.it. narečja (TAF 280), je neposredno prevzeta iz istr.it. oz. trž.it. scala 'lestev' (GDDT 573; Rosamani 954); prim. tudi istr.it. (Vodnjan) scale del caro 'lojtrnice pri vozu' (Rosamani ibid.), vse iz it. scala 'lestev' kot nadaljevanje lat. scāla 'id.' (REW 7637).

62. Vretena, končni del osi; fuselli (fusoli) della sala; Q. ALI 3601:

a) 3. 'bọkolå; 4. 'bọkola; 5. 'bọkolå; 6. 'bọkola; 7. 'bọkola

Istr. bokola se pomensko približuje trž.it. bùcola 'pesto' (GDDT 98; Rosamani 125); arh. 'obroček v pestu' (Rosamani ibid.), glede na vokalizem pa se ujema z bokola 'pesto', ki ga Pellegrini navaja za Žavlje pri Trstu (TAF 309) in je izpričano tudi v Gradežu v pomenu 'uhan' (Rosamani ibid.). Gre za italijanizem bòccola 'obroček v pestu', ki izhaja neposredno iz lat. buccula 'naličnik pri čeladi' (DEI I 548).

b) 9. 'birjå (za eti. gl. vpr. 29)

62a. Vijak pri osi; vite della sala; Q. ALI 3601:

a) 2. təm'pańa; 8. tam'påna 
Čeprav je istr. slov. oblika femininizirana, ni dvoma o njeni povezavi s sorodnimi rom. oblikami: prim. istr.it. (Poreč, Rovinj, Buje) tampagno 'šesterokotni vijak' (Rosamani 1136) oz. (Koper) tanpagno 'vijak' (Semi 296), trž.it. tampagno 'vijak z navojem' (GDDT 719), ben. tanpàgno 'matični navoj, vijak' (Durante 609), ben.dalm. tampàgno ‘šesterokotni vijak' (Miotto 207), reško tampagno 'vijak' (Samani 195). Gre $\mathrm{v}$ bistvu za besedo, ki zajema ves ben. areal, saj jo zasledimo v polez., padov. in beneč. narečju v pomenu 'klin, zatik' (Boerio 733; Prati EV 185). Njeno zadnje izhodišče je gr. tympánion 'bobnič'.

b) 5 . 'vidå

Istr. vida 'vijak' je rom. izposojenka, ki zajema ves ben. areal (trž., vič., padov., beneč., trev., polez., valsug.) (Boerio 793; GDDT 784; Rosamani 1220; Prati EV 200). Njeno zadnje izhodišče je zaradi podobnosti s trto lat. vitis 'trtna mladika; vitica' z metaplazmo (DEI V 4071; GDDT ibid.); prim. tudi furl. istopomensko vid (NP 1272) oz. vît (NP 1285).

63. Iglica, klin; acciarino della ruota del carro; Q. ALI 3602:

a) 6. vi'don

Istr. vidon je rom. avgmentativna izvedenka $\mathrm{k}$ vida (za eti. gl. vpr. 62a b), verjetno prevzeta iz trž.it. vidon 'vijačni žebelj (kovinska zapora narejena na vijak, ki zapira dno puškine cevi)' (GDDT 784; Rosamani 1221) oz. pomensko enakega furl. vidòn (NP 1273) in beneč. vidòn (Boerio 793), ki so vsi avgmentativi it. vite 'vijak' (DEI V 4071).

b)* 9. 'pảsolič

To slov. istr. dem. obliko je mogoče uskladiti le s pomensko enako istr.it. (Vodnjan) passéil 'iglica pri kolesu' (Rosamani 744) oz. kraš. pešil/pəšal/pasal 'id.' (SDLA-Ts 436); vse so izposojene iz istopomenskega furl. passèl (NP 711; TAF 304), katerega izhodišče je *paxéllus za lat. paxillus 'kolec' (REW 6318,2), iz katerega izhaja tudi stit. passillo 'id.' (DEI IV 2794).

c) 10. ka'peta

Istr. slov. izraz je dem. oblika (z rom. sufiksom -eta) slov. kápa 'pokrivalo; glavica žeblja; oje pri kolesu' (Bezlaj II 16 d.), ki je izposojeno iz lat. cappa 'vrsta pokrivala, plašč s kapuco', srlat. 'vrsta duhovniške obleke' (REW 1642). Bolj verjetno pa je, da je izposojen iz ben. (tudi beneč.) dem. capéta (capéta del schiopo o del manego del cortèlo) 'kapica' (Boerio 133; Durante 77), ki je najbrž istega izvora.

68. Oje; timone del carro; Q. ALI 3607a:

a) 1. tə่'mọn; 2. tə่muon; 4. tə่mun; 5. ta'mọn; 7. ta'mọn

b) 3. te'mọn; 8. te'mọn

c) 6. ta'muon; 10. ta'mọn

Navedene slov. istr. fonetične variante, ki so nedvomno v sorodstvu s kraš. tz'mun/ ta'muon 'oje' (SDLA-Ts 441), izhajajo iz furl. dublet temòn/tamòn 'oje pri vozu' (NP 1169; TAF 325), katerih zadnje izhodišče je lat. têmo, -ōne 'id.' (REW 8625).

č) 9. ti'muọn

Istr. slov. oblika, ki je sorodna $\mathrm{z}$ istr.it. (Vodnjan) agr. timon 'oje' (Rosamani 1155), trž.it. timon 'krmilo' (GDDT 735), beneč. timòn 'id.' (Boerio 748), furl. timòn 'id.' 
(NP 1169), belun. timón 'oje' (Tomasi 198), je tipična ben. izposojenka, katere zadnji vir je lat. temōne $(m)$ oz. *timōne(m) 'oje pri vozu' (DEI V 3792; REW 8625).

70. Jarem; giogo per due bovini; Q. ALI 3608:

1. 'dopli 'jarəm (za eti. gl. vpr. 3)

73. Spone pri jarmu; ritorte del giogo; Q. ALI 3610-1:

a) 1. 'tərta zə 'jarəm; 2. 'tərta; 3. 'tərtå; 4. 'tərta; 5. 'tərtå; 6. 'tərta; 7. 'tərta u्xəd 'jårmå; 8. 'tərta; 9. 'tərtå; 10. 'tərta

b) 5. 'čərtå

Istr. slov. izraz tərta (po paretimologiji čərta, kar je sicer vprašljivo) ni sl. porekla, pač pa romanskega. Uskladiti ga je treba namreč z istr.it. (Vodnjan, Koper, Piran, Oprtalj) tórta 'spona, vez pri jarmu' (Rosamani 1166) oz. (Bale) tòrta (Cernecca 114) oz. furl. (Claut) tórte (pl. z ben. fonetiko) 'bukove vezi pri jarmu' (TAF 407), prim. tudi furl. tuàrte/tuàrtie 'spona, vez (navadno usnjena ali iz vrbovja), s katero povežemo jarem na oje pri vozu' (NP 1222). Zadnje izhodišče je lat. tŏrtus 'zvit, upognjen' (REW 8809,1).

75. Jermeni okoli volovskih rogov; coregge intorno alle corna dei buoi aggiogati; Q. ALI 3612:

a) 5. 'rẹdnå (sing.)

Istr. slov. oblika je verjetno s posredovanjem istr.it. (Motovun) pl. rèdine 'vajeti' (Rosamani 867) oz. trž.it. rèdina 'uzda' (GDDT 515) sprejeta iz it. rédina 'id.' (DEI V 3220), ki je retroformacija lat. rětı̌nāculum 'uzda' (REW 7262) ali deverbal lat. rět ̌̆nēre 'zadržati' (REW 7263); prim. tudi beneč. rèdena 'uzda' (Boerio 560) in furl. redine 'id.' (NP 858).

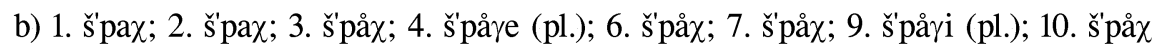

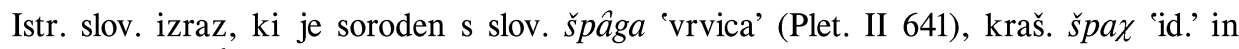
dalm. hrv. špâg 'id.' (Skok III 408), je prevzet iz trž.it. in istr.it. (Izola, Bale, Reka) spago 'vrvica' (GDDT 656; Cernecca 106; Rosamani 1061; Samani 180; Vascotto 293) oz. (Cres) agr. spag (Rosamani 1060), ki je beseda širšega ben. areala: prim. istopomensko bizj. spago (Domini 459), mugl. spag (DDM 158), ben.dalm. spàgo (Miotto 196), beneč. spago (Boerio 681) oz. it. knj. spàgo, srlat. (Benetke 1233) spagus, to pa iz poznolat. $s p \bar{a} c u(m)$ neznanega izvora (DELI 5, 1241).

77. Zavora; martinicca del carro; Q. ALI 3614:

5. f'rẹn

Istr. slov. fren je neposredno prevzeto iz istr.it. in trž.it. fren 'zavora' (GDDT 248), to pa iz it. freno 'uzda; zavora' (DEI III 1715), katerega zadnji vir je lat. frēnum 'uzda' (REW 3496); prim. tudi furl. frén 'zavora' (NP 344).

79. Lojtrnice; sbarre agli orli del carro; Q. ALI 3616:

a) 1. škə'lerje; 3. ška'ler (sing.); 5. škə'lerji; 9. ška'lerji

Istr. slov. oblika, ki se samo pomensko razlikuje od podobne kraš. škalier/škalier 'dno voza' (SDLA-Ts 433), je izposojena iz istr.it. (Rovinj) scaler 'prekla pri vozu' 
(Rosamani 955 in 956); prim. tudi furl. s'cialâr/s'cielâr 'dno voza' (NP 964; TAF 280), ki je razširjeno po vsej Furlaniji v tem pomenu; vse izvedeno iz it. scala (REW 7637).

\section{b) 3. ška'lọne; 6. ška'lọne}

To istr. slov. obliko je mogoče uskladiti z oblikovno enako, a pomensko nekoliko spremenjeno istr.it. (Poreč, Piran, Koper) scalòn 'dno voza; (Poreč) prekle nad lestvama kot opora za dno voza' (Rosamani 956) in trž.it. scalon 'prekla pri vozu; poseben tip voza, katerega dno je bilo oprto na tri prekle' (GDDT 575; Rosamani ibid.); prim. tudi furl. s'cialon 'dno posebnega voza za prevažanje sodov' (NP 965). Zadnji vir je ben. avgmentativ scalon 'kol' izveden iz it. scala (REW 7637).

c) 10. š'kåle (za eti. gl. vpr. 58c)

80. Zaboj pri dnu voza; cassa del letto del carro, laterali; Q. ALI 3617:

1. ka'sọn; 2. kə'suọn; 3. ka'sọn; 4. kə’sọn; 6. ka'sọn; 7. kə’sọn; 8. ka'sọn; 9. ka'suọn; 10. ka'sọn

Čeprav je istopomenska oblika kasón (z značilnim avgmentativnim sufiksom -on) razširjena tudi na furl. (Mereto di Tomba, Gorica - TAF 346; prim. tudi furl. cassòn - NP 109) in ben. območju (prim. beneč. cassòn - Boerio 146), mislim, da ni nujno za ustrezno istr. slov. obliko suponirati furl. porekla, saj je možno izhajati neposredno iz trž.it. cason 'zaboj' (GDDT 135; Rosamani 186), kar je prilagojeno po it. cassóne 'lesena skrinja za obleke, v rabi tudi kot sedež', to pa iz it. cassa (DEI I 796).

81. Drogi pri ozkem vozu; sbarre del carro stretto; Q. ALI 3618:

a) 4. 'bande

Istr. slov. pl. bande in kraš. pl. bando 'lojtrnice' (SDLA-Ts 448) imata ben. poreklo (prim. beneč., ben., trž.it., belun. banda 'stran, stranica' - Boerio 61; Durante 22; GDDT 53; Rosamani 63; Tomasi 33); možna je tudi primerjava s furl. bànde f. 'stran, stranica' (NP 35), v Pierisu bánde del kar ‘drogi pri ozkem vozu' (TAF 337). Vsi ti izrazi izhajajo iz got. bandwja 'znak' verjetno s posredovanjem prov. banda 'stran', prim. it. banda 'stran, stranica' (DEI I 424; DESF I 153).

b) 4. ška'lerji (za eti. gl. vpr. 79a)

c) 6. ška'lọne (za eti. gl. vpr. 79b)

č) 10. š'kåle (za eti. gl. vpr. 58c)

86. Voz na dve kolesi; baroccio; Q. ALI 3625:

a) 1. bi'roć; 2. bi'roč; 3. bi'lọć; 4. bi'roć; 7. bi'rọć

Istr. slov. biroč, nato pretvorjeno v biloč, je izposojeno iz trž.it. biroc' 'dvokolesni ali štirikolesni voz za prevoz blaga; koleselj (GDDT 74), iz katerega izhaja tudi kraš. biroč 'dvokolesni voziček' (SDLA-Ts 452). Doria (GDDT ibid.) suponira, da je to apokopirana oblika nekega $\mathrm{v}$ tržaščini neizpričanega birocio, ki ga je vsekakor možno izvajati iz dem. birocin 'voziček' in ki se navezuje na ben. biròcio 'dvokolesni voziček' (Durante 38), beneč. biròchio/biròzzo ‘štirikolesni voziček' (Boerio 81), it. biròccio 'dvokolesno vozilo' (DEI I 528). Izpad končnih zlogov je tipičen pojav nekate- 
rih trž.it. besed. Zato ga Doria $\mathrm{v}$ tem primeru ne pripisuje vplivu furl. biròz 'štirikolesno vozilo z dvema sedežema' (DESF I $221 \mathrm{~d}$.; NP 56), belun. biròč 'voziček' (Tomasi 39). Zadnje izhodišče za vse navedene izraze je vsekakor lat. *bīrǒtium 'dvokolesni voz' (REW 1114). Semantični prehod na 'štirikolesni voz' v it. dialektih ni popolnoma pojasnjen (DESF ibid.)

b) 5. ba'roć

Istr. slov. oblika baroč je po izpahu končnega zloga sorodna z ben. baròcio 'dvokolesni voziček' (Durante 38) oz. it. baròccio 'id.' (DEI I 443), to pa iz lat. *birŏtium 'dvokolesni voz' (REW 1114).

\section{c) 9 . bero'čin}

Istr. slov. dem. oblika je verjetno površna prikrojitev trž.it. birocin 'dvokolesni (včasih tudi ročni) voziček' (GDDT 74), iz katerega izhaja tudi kraš. (Sv. Križ) biročin 'id.' (SDLA-Ts 452), oz. it. biroccino 'id.' (za eti. gl. vpr. 86a); prim. tudi furl. birozzin 'id.' (NP 56).

c) 6. ka'les nə d've 'kuli

Beseda je prevzeta neposredno iz trž.it. cales 'koleselj; voziček' (GDDT 113; Rosamani 147), o katerem Doria domneva, da je apokopirana oblika ustrezne it. knj. calèsse 'poseben tip vozila' (DEI I 680) ali pa direktno povezana s frc. calèche 'id.', to pa iz nem. Kalesche, katerega zadnji vir je poljsko kolaska s posredovanjem češ. kolesa (DEI ibid.); prim. tudi beneč. calesse/calesso 'poseben štirikolesni voz' (Boerio 119).

87. Drogi voza na dve kolesi; stanghe del baroccio; Q. ALI 3626:

a) 1. ti'mọn; 8. ti'mọn (za eti. gl. vpr. 68č)

b) 3. te'mọn od bi'loćå; 4. d'va ta'muna nə bi'roći; 10. ta'mọn (za eti. gl. vpr. 68 $\mathrm{a}-\mathrm{c})$

c) 7. təmu'nẹla

Istr. slov. izraz, ki je nedvomno soroden $\mathrm{z}$ istr.it. (Rovinj) timonela oz. caro a timonela 'voz z dvema drogoma' (Rosamani 1155), je ben. izvora: prim. ben. (tudi beneč.) timonèla 'naprava, ki nadomešča oje pri vozu, ko uporabljajo enega samega konja' (Boerio 748; Prati EV 189), katerega zadnji vir je it. timonèlla 'dva droga povezana s prečnim drogom, na katera privežemo konja' (DEI V 3792), dem. oblika it. timone (za eti. gl. vpr. 68 č).

č) 1. štain $\gamma \mathrm{e}(\mathrm{pl}$.

Istr. slov. izraz, kateremu ustreza tudi slov. dial. štânga 'drog' (Plet. II 643) in katerega zadnji vir je germanski, se je verjetno zaradi areala razširil z romanskim posredovanjem, kar ugotavlja Doria (GDDT 679) tudi za istopomensko kraš. štanga. Izhajati je mogoče iz trž.it. in istr.it. (Koper, Piran, Bale) stanga 'drog' (GDDT ibid.; Cernecca 108; Rosamani 1088), kateremu ustreza istopomensko furl. stàngie (NP 1109 d.), ben. (tudi beneč.), belun., trev. stanga (Bernardi 395; Boerio 700; Durante 572; Tomasi 189) oz. it. knj. stànga (DELI 5, 1267). Zadnje izhodišče je got. ali long. stanga 'id.' (REW 8227).

90. Samokolnica; carriola; Q. ALI 3629:

a) 1 . bo'rẹla; 2 . bə่'ẹla; 4 . bo'rẹla; 5 . bo'rẹlå; 6 . bo'rela; 7. bo'rẹla 
Te istr. slov. oblike, katerim ustreza tudi kraš. (Medja vas) brriela 'dvokolesni voz' (SDLA-Ts 452), je mogoče uskladiti z naslednjimi pomensko sorodnimi: istr.it. (Piran) barela 'dvokolesni tovorni voziček' (Rosamani 70); ben. barèla 'kmečki voz z majhnimi robovi' (Durante 25); beneč. barèla 'voziček; koš za prevoz blaga, postavljen na dva droga, z dvema kolesoma, ki ga je vlekel en sam konj' (Boerio 64); belun. barèla a man 'ročni voziček za prevoz malte' (Tomasi 34); furl. barèla 'okorno prevozno sredstvo za gnoj ali drugo, sestavljeno iz dveh palic in ravne površine za nakladanje' (DESF I 167), dubleta k barèle 'dvokolesni voziček' (DESF ibid.; NP 40). $\mathrm{V}$ vseh teh primerih je očitna povezava $\mathrm{z}$ it. barèlla, dem. $\mathrm{k}$ it. bara 'nosilnica; krsta', katerega zadnje izhodišče je long. *bara (DEI I 439).

b) 3. kər' jọlå; 8. kar'jọla; 9. kər' juọlå; 10. kar'jọla

Izposojeno verjetno prek istr.it. (Rovinj) in trž.it. cariola 'samokolnica' (GDDT 132; Rosamani 174 d.), iz katerega izhaja tudi kraš. kərjola/kərjuola 'id.' (SDLA-Ts 454) - prim. tudi slov. karjôla/karôla 'vrsta voza' (Bezlaj II 20) - iz ben. (beneč., vič., polez., ver.) cariòla 'samokolnica' (Boerio 139; Durante 82; Prati EV 36), termina širšega sev.it. areala, ki je razmeroma zgodaj prešel tudi $\mathrm{v}$ it. knj. carriòla 'ročni voziček' (DEI I 782) in furl. cariòle 'samokolnica' (DESF I 313; NP 104 d.; TAF 385, ki navaja tudi furl. varianti karióla/kareóla). Gre za deminutiv ben. caro oz. it. carro 'voz', to pa iz lat. carrum 'id.', ki je verjetno galskega izvora (REW 1721).

94. Kolesnica; solco delle ruote; Q. ALI 3633:

a) 3. sa'ńau ot 'kul

Beseda, ki je nedvomno povezana tudi z reškim segnal 'znamenje, signal' (Rosamani 996) in furl. segnâl 'znamenje, znak' (NP 1005 d.), je v bistvu prikrojena po it. segnale 'dogovorjeno znamenje', katerega zadnji vir je poznolat. signāle iz lat. signum 'znak' (DEI V 3442).

b) 5. 'šeńo ut 'kul

Verjetno s posredovanjem istr.it. (Koper) in trž.it. segno 'znamenje, znak' (GDDT 609; Rosamani 996) je za to istr. slov. besedo zadnje izhodišče it. ségno 'znak, sled' (DEI V 3442), ki se je razvilo iz lat. siggnum 'vrez; znak', to pa iz lat. seco 'režem' (DEI ibid.); prim. tudi reško segno 'znak' (Samani 170), ben. oz. beneč. segno 'id.' (Boerio 641; Durante 499), furl. ségno 'id.' (NP 1006), ki ga Pellegrini (TAF 322) navaja tudi v pomenu 'kolesnica', ki je izpričan v slov. Istri.

Če upoštevamo razmerja med različnimi tipi navedenih 54 romanizmov, pridemo do naslednjih zaključkov, ki nam ponazarjajo podobo jezikovnih interferenc na slovenskem istrskem ozemlju:

1. najbolje zastopana je istrskoitalijanska plast, $\mathrm{v}$ katero uvrščam 28 terminov, ki so prešli v istrske slovenske govore iz sosednjega istrskoitalijanskega okolja. Čeprav 12 izposojenk (gl. znak ${ }^{* *}$ ) pozna tudi tržaško narečje, mislim, da je treba zaradi geografskega položaja vsekakor dati prednost istrskoitalijanskim govorom, kot neposrednemu izhodišču, pred tržaškoitalijanskim narečjem. V to skupino spadajo: 13.a fər-

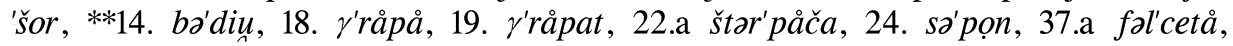
37.b ronko'nelå, **39. šk rr'šela, 49. 'baratat, 50.a 'šẹšla/50.b 'šešula, **58.a tavo'lac, **58.c šk'kålå, **62a.a tom'pańa, 63.b 'pásalič, **68.č ti'muọn, 73.a 'tarta oz. 73.b 


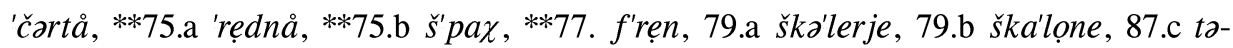
mu'nẹla, **87.č štainnye, 90.a bo'rela, **90.b kar'jolå, 94.a sa'ńau, **94.b 'šeńo;

2. sledi tržaškoitalijanska plast (12 terminov poleg zgoraj navedenih), ki se skupaj z istrskoitalijansko večinoma vključuje v širši beneški areal (kateremu vsekakor pripadajo izrazi 22.b ša'pẹta, 63.c ka'peta, 86.b ba'roć), z naslednjimi romanizmi: 9. mə'nica, 13.b šfalca'dọr, 15. 'bädalat, 25.b pi'kuọn, 58.b ška'leta, 62a.b 'vidå, 63.a vi'don, 80. ka'sọn, 81.a 'bande, 86.a bi'roć, 86.c bero'čin, 86.č ka'les;

3. srednjeveška furlanska plast je zastopana $\mathrm{z}$ eno tergestinsko izposojenko, in sicer 48.a pla'niẹr, medtem ko pripadajo novoveški furlanski plasti naslednji izrazi: 3 . 'dopli, 25.a 'pink, 36. 'makińa, 37.c 'rånčolå, 68.a tz'mọn oz. 68.b te'mọn oz. 68.c ta'muon;

4. iz knjižne italijanščine so prevzeti izrazi: 29. 'birja, 35. 'lamå, 48.b pə'nier, 62.a 'bọkolå;

5. sporadičen ali celo izjemen je primer dalmatinskohrvaške izposojenke, in sicer 50.č 'češsula, medtem ko je popolnoma odsotna latinska plast, ki sem jo zasledila v izrazoslovju drugih kmetijskih panog.

\section{Literatura}

ALI = Atlante Linguistico Italiano, neizdano gradivo, ki ga hranita Univerza $\mathrm{v} \mathrm{Tu}$ rinu in S.F.F. v Vidmu, razen tistega, ki ga izdaja ASLEF [= ALI].

ASLEF = Atlante Storico-Linguistico-Etnografico del Friuli-Venezia Giulia, ed. G. B. Pellegrini, Padova 1972-.

Bernardi = U. BERNARDI, Abecedario dei villani, Treviso 1981.

Bezlaj = F. BEZLAJ, Etimološki slovar slovenskega jezika, I (A-J), Ljubljana 1976; II (K-O), Ljubljana 1982; III (P-S), Ljubljana 1995.

Boerio = G. BOERIO, Dizionario del dialetto veneziano, II ediz., Venezia 1856.

Cernecca $=$ D. CERNECCA, Dizionario del dialetto di Valle d'Istria (= Bale), Trieste 1986.

DDM = D. ZUDINI - P. P. DORSI, Dizionario del dialetto muglisano, Udine 1981.

DEI = C. BATTISTI - G. ALESSIO, Dizionario etimologico italiano, Firenze 1950-57.

DELI = M. CORTELAZZO - P. ZOLLI, Dizionario etimologico della lingua italiana, 1-5 (A-Z), Bologna 1979-88.

DESF = G. B. PELLEGRINI - M. CORTELAZZO - A. ZAMBONI, Dizionario etimologico storico friulano, I (A-Ca), II (Ce-Ezzitâ), Udine 1984-.

Domini = S. DOMINI - A. FULIZIO - A. MINIUSSI - G. VITTORI, Vocabolario fraseologico del dialetto 'bisiàc', Bologna 1985.

Durante $=$ D. DURANTE - GF. TURATO, Dizionario etimologico veneto-italiano, Padova 1975. 
GDDT = M. DORIA - C. NOLIANI, Grande dizionario del dialetto triestino, Trieste 1987 .

Miotto = L. MIOTTO, Vocabolario del dialetto veneto-dalmata, II edizione riveduta e ampliata, Trieste 1991.

$\mathrm{NP}=$ G. A. PIRONA - E. CARLETTI - G. B. CORGNALI, Il nuovo Pirona, Vocabolario friulano, Udine 1977, ponatis originalne izdaje 1935.

Plet. = M. PLETERŠNIK, Slovensko-nemški slovar, I-II, Ljubljana 1894-95.

Prati EV = A. PRATI, Etimologie venete, Venezia - Roma 1968.

REW = W. MEYER-LÜBKE, Romanisches etymologisches Wörterbuch, III. izd., Heildelberg 1935.

Rosamani = E. ROSAMANI, Vocabolario giuliano, Bologna 1958, Trieste 1990 (I. ponatis).

Samani = S. SAMANI, Dizionario del dialetto fiumano, II. izdaja, Venezia 1980.

SDLA-Ts = R. COSSUTTA, Slovenski dialektološki leksikalni atlas Tržaške pokrajine, Trst 1987.

Semi = F. SEMI, El parlar s'ceto e neto de Capodistria (testi antichi e moderni, glossario, itinerario grafico, documentazione fotografica), Venezia 1983.

SKOK = P. SKOK, Etimologijski rječnik hrvatskoga ili srpskoga jezika, I-IV, Zagreb 1971-74.

TAF $=$ G. B. PELLEGRINI - C. MARCATO, Terminologia agricola friulana, Udine 1988-.

Tomasi $=$ G. TOMASI, Dizionario del bellunese arcaico (pravzaprav slovar poljedelskega izrazja v belunskem dialektu iz kraja Revine), Belluno 1983.

Turato-Durante = GF. TURATO - D. DURANTE, Vocabolario etimologico veneto-italiano, Padova 1985.

Vascotto = A. VASCOTTO, Voci della parlata isolana nella prima metà di questo secolo, Imola 1987.

Zamboni, Romanismi = A. ZAMBONI, Romanismi e altri strati linguistici nella Slavia triestina, Quaderni Patavini di linguistica, Monografie. 8 per Giovan Battista Pellegrini, Padova 1991.

\section{Krajšave}

$\begin{array}{llll}\text { agr. } & \text { agrarno } & \text { breš. } & \text { breško (Brescia) } \\ \text { arab. } & \text { arabsko } & \text { čak. } & \text { čakavsko } \\ \text { arh. } & \text { arhaično } & \text { češ. } & \text { češko } \\ \text { barb. } & \text { barbarsko } & \text { dalm. } & \text { dalmatinsko } \\ \text { belun. } & \text { belunsko } & \text { dem. } & \text { deminutiv(no) } \\ \text { ben. } & \text { beneško (nanaša se na pokrajino Veneto) } & \text { dial. } & \text { dialektično } \\ \text { beneč. } & \text { benečansko (nanaša se na mesto Benetke) } & \text { emil. } & \text { emilijansko } \\ \text { bizj. } & \text { bizjaško } & \text { eti. } & \text { etimologija }\end{array}$




$\begin{array}{llll}\text { frc. } & \text { francosko } & \text { polez. } & \text { polezinsko (Polesine) } \\ \text { furl. } & \text { furlansko } & \text { pom. } & \text { pomorsko } \\ \text { germ. } & \text { germansko } & \text { poznolat. } & \text { poznolatinsko } \\ \text { got. } & \text { gotsko } & \text { prov. } & \text { provansalsko } \\ \text { gr. } & \text { grško } & \text { Q. } & \text { Questionario (vprašalnica) } \\ \text { hrv. } & \text { hrvaško } & \text { rom. } & \text { romansko } \\ \text { it. } & \text { italijansko } & \text { rover. } & \text { roveretansko (Rovereto) } \\ \text { istr. } & \text { istrsko } & \text { sev.it. } & \text { severnoitalijansko } \\ \text { istr.it. } & \text { istrskoitalijansko } & \text { sl. } & \text { slovansko } \\ \text { kjož. } & \text { kjožotsko (Chioggia) } & \text { slov. } & \text { slovensko } \\ \text { knj. } & \text { knjižno } & \text { srlat. } & \text { srednjelatinsko } \\ \text { kor. } & \text { koroško } & \text { stit. } & \text { staroitalijansko } \\ \text { kraš. } & \text { kraško } & \text { terg. } & \text { tergestinsko } \\ \text { lat. } & \text { latinsko } & \text { trent. } & \text { trentinsko (Trento) } \\ \text { long. } & \text { longobardsko } & \text { trž. } & \text { tržaško } \\ \text { ilj.it. } & \text { miljskoitalijansko } & \text { trž.it. } & \text { tržaškoitalijansko } \\ & \text { (Milje pri Trstu) } & \text { trev. } & \text { treviško (Treviso) } \\ \text { mugl. } & \text { muglizansko } & \text { valsug. } & \text { valsugansko (Valsugana) } \\ \text { nem. } & \text { nemško } & \text { ver. } & \text { veronsko (Verona) } \\ \text { notr. } & \text { notranjsko } & \text { vič. } & \text { vičentinsko (Vicenza) } \\ \text { padov. } & \text { padovansko } & \text { vulg. lat. } & \text { vulgarno latinsko }\end{array}$

Prispelo maja 1996, sprejeto decembra 1996

Received May 1996, accepted December 1996

\section{Romanske izposojenke v poljedelski terminologiji Slovenske Istre}

Za svojo doktorsko disertacijo z naslovom Poljedelska in vinogradniška terminologija v govorih Slovenske Istre je avtorica v letih 1988-90 pod mentorstvom prof. Logarja izvedla terensko raziskavo v 10 raziskovalnih točkah, enakomerno pokrivajočih ozemlje vse Slovenske Istre (1. Malija; 2. Padna; 3. Krkavče; 4. Gažon; 5. Šmarje; 6. Koštabona; 7. Pomjan; 8. Boršt; 9. Marezige; 10. Trebeše). Z vidika izrazja različnih kmetijskih panog je obsežno gradivo razdelila na 7 poglavij (I. Kmečko orodje, pridelki, delo na polju in v hlevu; II. Na vrtu in v sadovnjaku; III. Vinogradništvo; IV. Nekatere rastline in drevesa in opravila z njimi; V. Reja živali; VI. Čebelarstvo; VII. Oljarstvo) in ga nato etimološko utemeljila. Prispevek je kratek povzetek prvega poglavja, $\mathrm{v}$ katerem avtorica obravnava romanizme $\mathrm{v}$ izrazju za kmečko orodje in skuša ugotoviti, iz katerega od sosednjih romanskih narečij oz. knjižnega italijanskega jezika so bili prevzeti. Pri razčlembi romanskih izposojenk ugotavlja

Znak * označuje posebno kategorijo romanizmov, in sicer izvedenke s slov. predponami, priponami in končnicami, številka, ki je navedena pred romanizmom, pa zaporedje raziskovalnih točk; številka pred posameznimi vprašanji je zaporedna številka vprašalnice, ki sem jo izdelala za to raziskavo na podlagi različnih vprašalnic. 
več plasti: istrskoitalijansko in tržaškoitalijansko plast, ki sta najbolje zastopani in ju avtorica uokvirja $\mathrm{v}$ širši beneški areal; furlansko plast, ki sega od srednjeveške do novoveške; italijansko plast, v katero uvršča izraze, ki so neposredno prevzeti iz knjižne italijanščine. Sporadičen je primer dalmatinskohrvaške izposojenke, medtem ko je popolnoma odsotna latinska plast, ki jo je avtorica zasledila $\mathrm{v}$ izrazju drugih kmetijskih panog. Razprava skuša tako začrtati tokove istrske romanizacije, ki so v različnih obdobjih vplivali na narečno diferenciacijo tega dela slovenskega ozemlja.

\section{Romance Borrowing in the Agricultural Terminology of Slovene Istria}

For her doctoral dissertation entitled Agricultural and Viticultural Terminology in the Dialects of Slovene Istria, the author (in 1988-90 under the mentorship of Prof. Tine Logar) conducted a field investigation of ten localities, equally distributed over the entire region of Slovene Istria (1. Malija; 2. Padna; 3. Krkavče; 4. Gažon; 5. Šmarje; 6. Koštabona; 7. Pomjan; 8. Boršt; 9. Marezige; 10. Trebeše). The copious material is divided into seven chapters covering various aspects of agriculture (I. Tools, crops, work in the fields and in the barn; II. Garden and orchard; III. Viticulture; IV. Certain plans and trees and operations connected with them; V. Animal husbandry; VI. Beekeeping; VII. Oil production), which are then treated etymologically. The paper is a short summary of the first chapter of the dissertation, in which the author treats Romance borrowings in the terminology for agricultural tools and attempts to discover from which form of Romance - whether from neighboring Romance dialects or standard Italian - a given term was borrowed. The analysis of Romance borrowings reveals several layers: an Istrian Italian and Trieste Italian layer, which is most frequently attested and which is placed in the framework of a wider Venetian areal; a Friulian layer, which extends from the medieval to the modern period; an Italian layer, which includes terms that are taken directly from standard Italian. Occasionally one finds also Dalmatian Croatian borrowings. However, there is no trace of a Latin layer, which the author has observed in the terminology of other branches of agriculture. Thus the study attempts to reveal of the paths of Istrian Romanization and to delineate the linguistic geography of this Slovene territory. 